\title{
Sosialisasi Aplikasi Pembelajaran Interaktif Berbasis Multimedia
}

\author{
Raden Wirawan ${ }^{*}$, Muhammad Awal Nur ${ }^{2}$ \\ ${ }^{1,2}$ Program Studi Sistem Komputer, STMIK Bina Adinata, Bulukumba, Sulawesi Selatan, Indonesia \\ Email: ${ }^{1}$ liliraden12790@gmail.com, ${ }^{2}$ awalnur10@gmail.com
}

\section{INFORMASI ARTIKEL}

\section{Data artikel:}

Naskah masuk, 15 Januari 2021

Direvisi, 05 Maret 2021

Diterima, 11 Mei 2021

\section{Kata Kunci:}

Aplikasi Pembelajaran

Interaktif

Keterampilan

Multimedia

Sosialisasi

\begin{abstract}
ABSTRAK
Abstract- The socialization of multimedia-based interactive learning applications is a community service for STMIK Bina Adinata lecturers at Inpres Elementary School Number 207 Linrungloe which aims to increase knowledge and understanding of educators, especially classroom teachers about multimedia-based learning applications. This activity is in the form of counselling about an interactive multimediabased learning application using a computer. The method used in this service is socialization and training, starting with an explanation of the material about applications, interactive learning and multimedia, after which an introduction to the use of applications to educators and finally explaining the use of applications to students. The results of this socialization increase the understanding and ability of educators in the application of multimedia-based learning and increase the learning interest of SDI 207 Linrungloe students in the learning process in the classroom using multimedia-based learning applications.
\end{abstract}

\begin{abstract}
Abstrak- Sosialisasi aplikasi pembelajaran interaktif berbasis multimedia merupakan pengabdian masyarakat dosen STMIK Bina Adinata di Sekolah Dasar Inpres Nomor 207 Linrungloe yang bertujuan untuk meningkatkan pengetahuandan pemahaman tenaga pendidik khususnya guru kelas tentang aplikasi pembelajaran berbasis multimedia. Kegiatan ini berupa penyuluhan tentang sebuah aplikasi pembelajaran berbasis multimedia yang interaktif menggunakan komputer. Metode yang digunakan dalam pengabdian ini adalah sosialisasi dan pelatihan dimulai dengan penjelasan materi tentang aplikasi, pembelajaran interaktif dan multimedia, setelah itu pengenalan penggunaan aplikasi ke tenaga pendidik dan terakhir menjelaskan penggunaan aplikasi ke peserta didik. Hasil dari sosialisasi ini meningkatkan pemahaman dan kemampuan tenaga pendidik dalam penerapan pembelajaran berbasis multimedia dan meningkatkan minat belajar peserta didik SDI 207 Linrungloe dalam proses belajar di kelas menggunakan aplikasi pembelajaran berbasis multimedia.
\end{abstract}




\section{Korespondensi:}

\section{Raden Wirawan}

Program Studi Sistem Komputer, STMIK Bina Adinata, Bulukumba, Sulawesi Selatan, Indonesia Jl. Serikaya No. 8 Bulukumba, Sulawesi Selatan, Indonesia

\section{PENDAHULUAN}

Dalam dunia pendidikan, ada beberapa alasan yang melatar belakangi pentingnya pemanfaatan pengunaan teknologi informasi, terutama dalam meningkatkan mutu pendidikan di semua jenjang pendidikan untuk mengatasi kesenjangan layanan pendidikan akibat dari kondisi geografis yang berbedabeda, dan perubahan sosial budaya masyarakat yang bergerak dinamis.

Pengunaan teknologi informasi dan komunikasi (TIK) di dunia pendidikan akan dapat memberikan manfaat terutama dalam mempermudah dan meningkatkan kinerja pendidikan, meningkatkan efektifitas dan produktifitas pendidikan, lebih fleksibel dan mempermudah pengoperasian pendidikan di semua jenjang pendidikan termasuk Sekolah Dasar.

Pendidikan di Sekolah Dasar pada hakekatnya merupakan pendidikan yang lebih mengarahkan dan lebih banyak memotivasi siswa untuk belajar. Pemanfaatan teknologi komunikasi dan informasi telah memberikan dampak kemajuan terhadap dunia pendidikan, salah satu contoh penggunaan teknologi dalam dunia pendidikan adalah dengan memanfaatkan teknologi komputer sebagai alat bantu pembelajaran(Wirawan et al., 2020). Pemanfaatan media pembelajaran merupakan suatu upaya sistematis dan kreatif dalam rangka menciptakan pengalaman yang dapat membelajarkan siswa sehningga pada akhirnya sekolah akan mampu menghasilkan lulusan yang berkualitas (Priyanto, 2009).

Pembelajaran merupakan suatu sistem yang terdiri dari perencanaan, pelaksanaan dan evaluasi. Sistem ini saling berinteraksi satu dengan yang lainnya, apabila salah satu sistem tersebut mengalami masalah maka akan mempengaruhi yang lain, sehingga proses pembelajaran tidak akan berjalan dengan baik(Wijaya et al., 2020). Agar pembelajaran memiliki kualitas yang bagus, maka guru dihadapkan pada tantangan bagaimana menciptakan suasana pembelajaran yang menyenangkan bagi anak dan anak menjadi senang untuk belajar. Karena guru merupakan tenaga profesional yang mempunyai tugas utama mendidik, mengajar, membimbing, mengarahkan, melatih, menilai, dan mengevaluasipeserta didik pada pendidikan anak usia dini dan jalur pendidikan formal, pendidikan dasar dan pendidikan menengah.

Salah satu penggunaan teknologi dalam pembelajaran yaitu berupa aplikasi pembelajaran yang mengacu pada teknologi berbasis multimedia. Dengan multimedia akan dapat dibuat media pembelajaran yang lebih menarik dan interaktif. Penggunaan multimedia mampu membuat suatu terobosan baru dalam menciptakan dinamika kemasan data dan informasi dengan cara yang berbeda, bukan dengan teks statis tetapi dengan animasi teks, gambar, suara serta video(Syam, 2017). Pembelajaran berbasis multimedia dapat memahami gaya belajar anak selain itu multimedia yang di desain dengan baik juga dapat meningkatkan hasil belajar peserta didik. Tentu hal ini sangat mendukung sistem pembelajaran yang mudah, efektif dan menyenangkan.

Berdasarkan hasil wawancara dengan Kepala Sekolah Sekolah Dasar Inpres Nomor 207 Linrungloe bahwa saat ini tenaga pendidik yang ada disekolah merasa kesulitan dalam penerapan metode pembelajaran yang diterapkan dalam kurikulum 2013. Sebagian besar guru belum terbiasa dalam penggunaan media pembelajaran saat mengajar, masih menggunakan cara konvensional dengan pemberian penjelasan dengan buku dan alat peraga seadanya. Selain itu, keterbatasan alat pendukung yang berbasis komputerisasi disekolah menjadi salah satu kendala tenaga pendidik dalam proses belajar mengajar.

Oleh karena itu, dalam membantu mewujudkan visi sekolah SDI 207 Linrungloe yaitu Mewujudkan Sekolah Yang Berprestasi Terampil Dan Berbudi Pekerti Luhur Berpijak Pada Iman Dan Taqwa, kami dosen dari program studi sistem komputer STMIK Bina Adinata melaksanakan kegiatan pengabdian 
kepada masyarakat berupa sosialisasi aplikasi pembelajaran interaktif berbasis multimedia.

Dimana aplikasi mempunyai arti yaitu suatu program yang siap untuk digunakan yang dibuat untuk melaksanakan suatu fungsi bagi pengguna jasa aplikasi serta penggunaan aplikasi lain yang dapat digunakan oleh suatu sasaran yang akan dituju. Dalam konteks pembelajaran, interaktif merupakan sistem yang menyajikan materi video rekaman dengan pengendalian komputer kepada penonton yang tidak hanya mendengar dan melihat video dan suara, tetapi juga memberikan respon yang aktif dan respon itu yang menentukan kecepatan dan frekuensi penyajian(Wirawan, 2020).

Multimedia adalah suatu integrasi elemen beberapa media (audio, video, grafik, teks, animasi, dan sebagainya) menjadi sebuah kesatuan yang sinergis dan simbiosis yang memberikan hasil lebih menguntungkan bagi pengguna ketimbang elemen media secara individual(Mulia, 2020). Selain itu, Multimedia interaktif adalah perpaduan teks, gambar, animasi, suara, dan video menuntut keterlibatan banyak indera dalam proses belajar (Novitasari, D, 2016).

American Heritage Dictionary mendefinisikan multimedia sebagai sebuah sistem yang terdiri dari pengontrolan berkomputer, integrasi, manipulasi, perwakilan, penyimpanan dan komunikasi berbagi informasi yang dikodekan melalui media time-dependent dan media timeindependent. Peranan multimedia dalam proses pembelajaran adalah membantu keefektifan dan penyampaian isi materi dalam proses pembelajaran serta dapat membangkitkan motivasi, minat dan meningkatkan pemahaman siswa serta menyajikan data dengan menarik dan terpercaya (Hakim \& Windayana, 2012)

Tujuan dari kegiatan ini adalah meningkatkan pengetahuan dan pemahaman tenaga pendidik khususnya guru kelas tentang aplikasi pembelajaran berbasis multimedia dan meningkatkan motivasi belajar siswa. Keberhasilan kegiatan Sosialisasi aplikasi pembelajaran interaktif berbasis multimedia ini diharapkan memberi luaran kepada Mitra. yaitu :

1) Meningkatkan pengetahuan tenaga pendidik SDI 207 Linrungloe tentang aplikasi pembelajaran berbasis multimedia.
2) Meningkatkan motivasi belajar peserta didik SDI 207 Linrungloe dalam proses pembelajaran berbasis multimedia khususnya materi pelajaran matematika di kelas.

\section{METODE PELAKSANAAN}

Metode yang digunakan dalam kegiatan penyuluhan ini adalah metode deskriptif. Metode ini penulis berusaha untuk mengumpulkan masalah aktual, menyusun, dan mengklasifikasikan data dengan langkahlangkah yang ditempuh(Isnaini \& Herliani, 2020). Pada kegiatan ini penyuluhan dilaksanakan dengan langkah-langkah berikut:

a. Pengumpulan data dengan observasi dan wawancara;

b. Persiapan mengajar yang terdiri atas persiapan waktu, materi dan teknik pembelajaran;

c. Pelaksanaan penyuluhan dengan proses pembelajaran di kelas (pelaksanaan kegiatan belajar mengajar); dan

d. Laporan hasil penyuluhan/hasil pembelajaran.

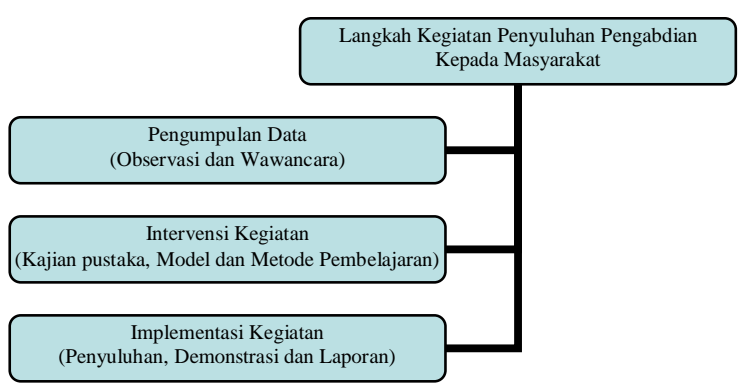

Gambar 1. Langkah Kegiatan

\section{HASIL DAN PEMBAHASAN}

\subsection{Peserta Kegiatan}

Peserta dalam kegiatan pengabdian masyarakat ini adalah tenaga pendidik SDI 207 Linrungloe yang terdiri dari 14 orang enam guru, empat honorer, satu operator dan kepala sekolah serta peserta yang mengikuti demonstrasi pembelajaran yaitu peserta didik kelas IV, V dan VI SDI 207 Linrungloe.

\subsection{Lokasi dan Waktu Kegiatan}

Kegiatan ini dilakukan di Sekolah Dasar Inpres Nomor 207 Linrungloe yang berlokasi di desa Bangkalaloe Kecamatan Bontoramba Kabupaten Jeneponto pada tanggal 20 - 23 Januari 2020. Dimulai 
pada pukul 09.00 wita sampe 14.00 wita di ruang kelas SDI 207 Linrungloe

\subsection{Pelaksanaan Kegiatan}

Kegiatan sosialisasi ini diawali dengan penjelasan teknis acara kepada kepala sekolah SDI 207 Linrungloe. Pertama kegiatan ini dilakukan di ruang kelas dimulai dengan pembukaan oleh kepala sekolah, berikutnya pemaparan materi secara deskriftif oleh tim pengabdi meliputi: defenisi aplikasi, kegunaan aplikasi, pembelajaran matematika, pembelajaran interaktif dan multimedia kemudian dilanjutkan dengan diskusi serta tanya jawab seputar aplikasi pembelajaran interaktif berbasis multimedia.

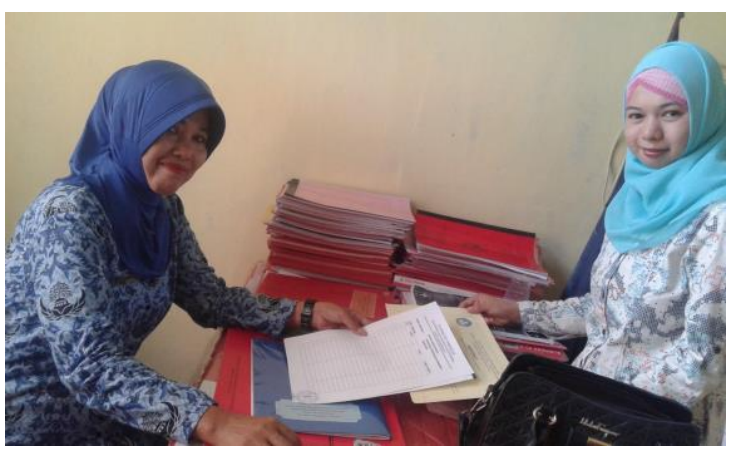

Gambar 2. Penjelasan Teknis Acara kepada Kepala Sekolah SDI 207 Linrungloe

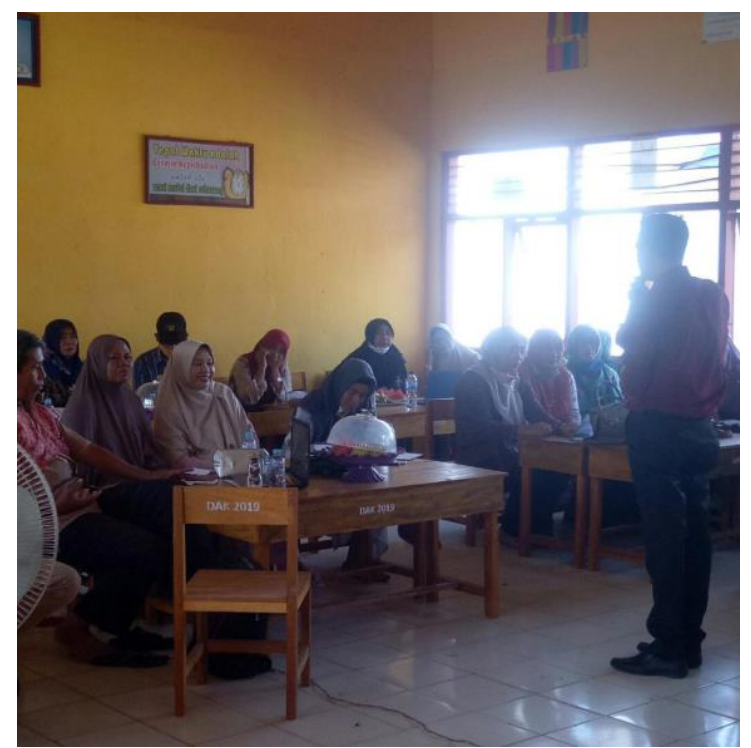

Gambar 3. Pemaparan Materi dan Diskusi dengan Tenaga Pendidik

Dari hasil diskusi tampak tenaga pendidik SDI 207 Linrongloe sangat antusias untuk mengetahui cara menggunakan aplikasi pembelajaran multimedia dalam proses belajar mengajar dengan memanfaatkan komputer.
Karena masih kurangnya pengetahuan guru di SDI 207 tentang aplikasi pembelajaran multimedia dan masih kurangnya perangkat komputer/Laptop dan kemampuan guru dalam menggunakan komputer dalam pembelajaran.

Selanjutnya kegiatan dilanjutkan dengan demonstrasi langsung aplikasi pembelajaran matematika interaktif ke peserta didik SDI 207 Linrungloe. Dalam kegiatan ini tampak peserta didik sangat bersemangat dan termotivasi dalam belajar matematika, rasa ingin tahu dan belajar dengan cara yang baru meningkatkan minat belajar peserta didik SDI 207 Linrongloe.

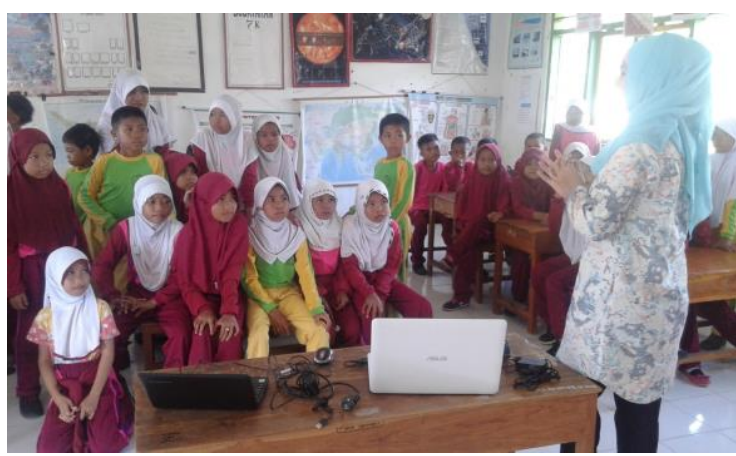

Gambar 4. Demonstrasi Pembelajaran Matematika dengan Aplikasi Multimedia

Dengan adanya program pengabdian pada masyarakat yang sudah dilaksanakan di sekolah ini diharapkan dapat menambah pengetahuan dan keterampilan tenaga pendidik menggunakan komputer dalam proses belajar mengajar dan meningkatkan pemahaman tentang aplikasi pembelajaran multimedia. Disamping itu dengan adanya sosialisasi ini, diharapkan mampu meningkatkan minat belajar peserta didik dalam proses pembelajaran sehingga berdampak pada hasil belajar dan prestasi siswa di atas Standar Kriteria Ketuntasan Minimal (KKM) dan Kurikulum yang berlaku.

Ketercapain tujuan kegiatan dinilai dari tingkat pemahaman pengetahuan tenaga pendidik SDI Nomor 207 Linrungloe dalam memaparkan kembali materi tentang aplikasi, pembelajaran interaktif dan multimedia serta kemampuan tenaga pendidik SDI 207 Linrungloe dalam mengaplikasikan contoh aplikasi pembelajaran multimedia saat sosialisasi. 


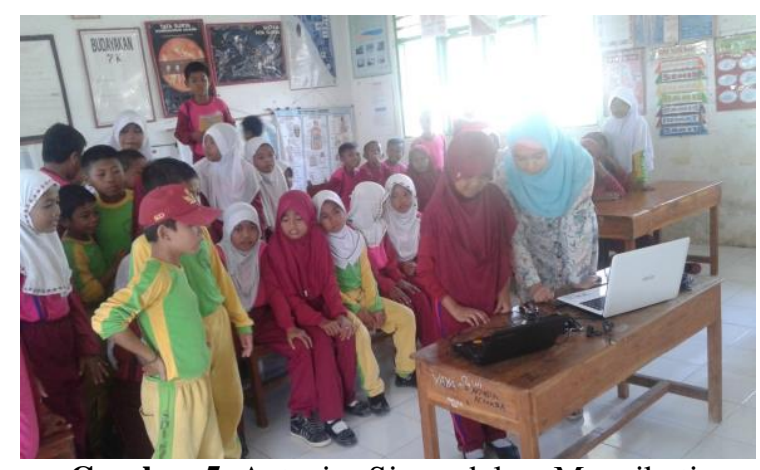

Gambar 5. Antusias Siswa dalam Mengikuti Pembelajaran Multimedia

Selain itu, meningkatnya antusias peserta didik kelas empat lima dan enam dalam mengikuti demosntrasi pembelajaran menggunakan aplikasi multimedia yaitu aplikasi pembelajaran matematika interaktif berbasis multimedia yang dilakukan diruang kelas enam SDI Nomor 207 Linrungloe.

\section{KESIMPULAN}

Kegiatan sosialisasi aplikasi pembelajaran interaktif berbasis multimedia sukses dan berjalan lancar diadakan di Sekolah Dasar Inpres Nomor 207 Linrungloe di desa Bangkalaloe Kecamatan Bontoramba Kabupaten Jeneponto. Kegiatan ini mendapa sambutan sangat baik dari kepala sekolah dan para tenaga pendidik di sekolah. Kegiatan ini menambah pengetahuan para tenaga pendidik disekolah SDI 207 Linrungloe tentang penggunaan media pembelajaran berbasis komputer yang dapat digunakan dalam proses pembelajaran dikelas. Kegiatan ini juga meningkatkan motivasi belajar siswa dalam proses pembelajaran. Hal dapat dilihat dari hasil angket yang di berikan kepada siswa sebelum dan sesudah pelaksanaan kegiatan. Hasil rata-rata motivasi siswa sebelum penggunaan aplikasi adalah $50 \%$ berada pada kategori rendah dan sesudah penggunaan aplikasi dalam proses pembelajaran rata-rata motivasi siswa adalah $75 \%$ berada pada kategori tinggi. Hal ini menandakan motivasi belajar siswa meningkat setelah penggunaan aplikasi dalam proses pembelajaran khususnya pada mata pelajaran matematika. Hasil angket juga diperoleh bahwa sebagian besar siswa senang belajar matematika dengan menggunakan multimedia dalam proses pembelajaran.

Adapun saran untuk kegiatan pengabdian selanjutnya yaitu waktu pelaksanaan kegiatan pengabdian perlu ditambah agar tujuan kegiatan dapat tercapai sepenuhnya, dan perlu adanya kegiatan lanjutan yang berupa pelatihan sejenis yang diselenggarakan secara periodik sehinga kemampuan dalam pengaplikasian pembelajaran dapat meningkat secara maksimal.

\section{UCAPAN TERIMA KASIH}

Terima kasih kepada STMIK Bina Adinata atas segala dukungan dalam kegiatan pengabdian kepada masyarakat sehingga berjalan lancar dan kepada Kepala Sekolah SDN Inp 270 Linrungloe yang telah berkenan menjadi mitra dalam kegiatan pengabdian kepada masyarakat.

\section{DAFTAR PUSTAKA}

Hakim, r a., \& Windayana, h.(2012). Pengaruh Penggunaan Multimedia Interaktif dalam Pembelajaran Matematika untuk Meningkatkan Hasil Belajar Siswa SD. EduHumaniora,4(2). https://doi.org/10. 17509/eh.v4i2

Isnaini, h., \& herliani, y. (2020). Penyuluhan pembelajaran menulis puisi berbasis karakter di smk profita kota bandung tahun ajaran 2019-2020. Community development journal, 1(2), 78-83.

Mulia, h. R. (2020). Pelatihan mendesain pembelajaran berbasis multimedia di kalangan guru min 11 aceh tenggara. Jurnal ilmiah pengabdian, 6(2), 84-91. Https://doi.org/https://doi.org/10.21107/p angabdhi.v6i2.7602

Novitasari,D.(2016). Pengaruh Penggunaan Multimedia Interaktif terhadap Kemampuan Pemahaman Konsep Matematis Siswa. Fibonacci,2(2),8-18. https://doi.org/10.24853/fbc.2.2.8-18

Priynto, D.(2009). Pengembangan Multimedia Pembelajaran berbasis Komputer. Insania, 14 (1), 1 -13

Syam, n. (2017). Pengembangan media tutorial pembelajaran ipa berbasis web. Jurnal pendidikan fisika, 5, 156-174.

Wijaya, i. P., kurniawati, e., iswantiningtyas, v., \& dwiyanti, 1. (2020). Workshop perencanaan pembelajaran pendidikan 
anak usia dini berbasis loose parts.

Communnity development journal, 1(2), 84-88.

Wirawan, r. (2020). Aplikasi pembelajaran sistem pencernaan manusia menggunakan linear congruent method berbasis. In $\mathrm{m}$. S. Hardi hamzah, s.pd. (ed.), prosiding seminar nasional fdi sulsel (issue 1, pp. 1-6). Fdi dpd sulawesi barat.
Http://sulsel.fdi.or.id/semnas

Wirawan, r., awal nur, m., \& syahraeni, r.

(2020). Aplikasi pembelajaran matematika interaktif berbasis multimedia. Jartika : jurnal riset teknologi dan inovasi pendidikan, 3(1), 75-83.

Https://doi.org/10.36765/jartika.v3i1.28 